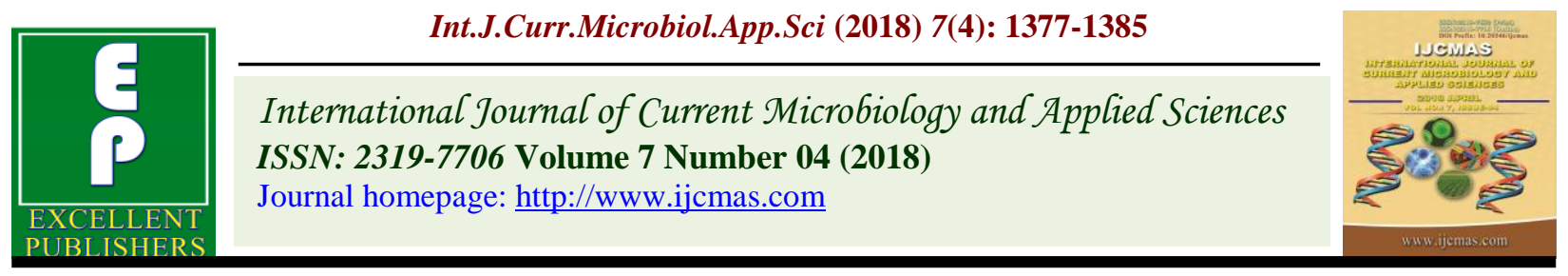

Original Research Article

https://doi.org/10.20546/ijcmas.2018.704.154

\title{
Variability of Rapeseed and Mustard in Manipur and its Reaction to Albugo candida
}

\author{
Tusi Chakma, Bireswar Sinha*, Th. Renuka Devi and Atom Anupama Devi
}

Department of Plant Pathology, College of Agriculture, CAU Imphal-795004, India

*Corresponding author

\section{A B S T R A C T}

\begin{tabular}{|l|}
\hline Ke y w o r d s \\
$\begin{array}{l}\text { Albugo candida, Artificial } \\
\text { inoculation, Cluster } \\
\text { analysis, Rapeseed and } \\
\text { mustard, RAPD }\end{array}$ \\
\hline Article Info \\
\hline $\begin{array}{l}\text { Accepted: } \\
12 \text { March } 2018 \\
\text { Available Online: } \\
10 \text { April } 2018\end{array}$ \\
\hline
\end{tabular}

\section{Introduction}

Rapeseed and Mustard is the second most important oilseed crop in India after soybean. Rapeseed and Mustard is a Rabi season crop sown during Oct-Nov and harvested during March-April. It belongs to genus brassica of the family Cruciferae. In India, it is commercially grown in an area of 6.70 Mha with a production of $7.96 \mathrm{Mt}$ accounting for a yield of $1188 \mathrm{~kg} / \mathrm{ha}$ (DOAC, 2014). The crop is known to be attacked by number of fungal, bacterial and viral diseases. More than twenty diseases are known to affect the rapeseed and mustard group of crops in India, but diseases like White rust and Downy mildew are the major consequences because of their global distribution and heavy yield losses. Albugo candida was first discovered in New Zealand in 1884 by William Colenso, possibly having been introduced accidentally on weeds or food crops (Norton and de Lange, 1999). The oomycete parasite Albugo candida (Pers.) Kuntze is a widespread pathogen and it causes significant damage in economically important crops and weeds (Fa'rr et al., 1989). Its attacks as many as 63 genera 241 species (Saharan and Verma, 1992), of which Brassica and Rhapanus are the most cultivated hosts. This organism causes white rust or white blister diseases in above-ground plant tissues. Yield losses from 23 to 54.50 per cent due to both phases (leaf and stag head) of white rust have been reported from India (Saharan, 1991). Staghead formation (systemic infection) due to white rust and/or 
mixed infection of white rust and downy mildew causes losses in yield from 23 to 60 per cent (Saharan and Verma, 1992). In Manipur, mustard is one of the important leafy vegetables prefers by everyone, but due to white rust its quality and yield is affected. Therefore the present investigation was undertaken to find out the reaction of white rust (Albugo candida) against local cultivars/genotypes of Rapeseed and Mustard in Manipur and RAPD analysis of cultivars/genotypes.

\section{Materials and Methods}

\section{Artificial inoculation}

The experiments were conducted during the crop season of year 2016-17 at Department of Plant Pathology, College of Agriculture, CAU, Imphal on 20 cultivars/genotypes of rapeseed and mustard. Plants were inoculated at cotyledon stage i.e. 7 DAS. Inoculum was prepared by collecting fresh zoosporangia in sterilized distilled water from naturally infected leaves with Albugo candida. Beaker containing zoosporangia suspension was kept at $4^{0} \mathrm{C}$ for $2 \mathrm{hrs}$ to facilitate germination of zoosporangia. The zoosorangial suspension was made $2.5 \times 10^{5} / \mathrm{ml}$ with the help of haemocytometer (Trimali, 2012). The suspension was sprayed on leaves of 20 test plants in the evening with the help of small hand sprayer. Observations of disease severity on leaves were recorded at 14, 21, 28 and 35 days after inoculation (DAI) using rating scale 0-9 (Williams, 1985).

\section{RAPD analysis of cultivars or genotypes}

DNA from 20 rapeseed and mustard cultivars/genotypes Viz., CAULC-1, CAULC2, CAULC-3, CAULC-4, KRANTI, PM-21, GM-2, URBASHI, CAUMC-8, CAUMC-10, CAUMC-11, CAUMC-12, CAUMC-14, CAUMC-15, CAUMC-17, CAUMC-20, CAUMC-21, CAUMC-22, CAUMC-23 and
CAUMC-24 (Source: AICRP (RARESEED AND MUSTARD) CAU, IMPHAL) were isolated from actively growing fresh leaves of 20 to 25 days old seedlings using HiPurA DNA isolation kit (HiMedia, India). The above extracted genomic DNA from each cultivars/genotypes was amplified and PCR amplification was done by using OPB-01, OPB-08and OPD-13 RAPD primers.

\section{DNA amplification by PCR and electrophoresis}

The amplification conditions originally recommended by Williams et al., (1990) were applied with slight modifications. The total volume of PCR cocktail was $25 \mu \mathrm{l}$ per sample. $0.5 \mu 1$ genomic DNA added in PCR cocktail. DNA Amplifications were performed using PX2 thermal cycler (Thermo Electron Corporation). The PCR tubes were set on the wells of the thermo cycler plate and Then, the machine was run according to the following setup: Initial denaturation at $94^{\circ} \mathrm{C}$ for 4 min; denaturation at $94^{\circ} \mathrm{C}$ for $1 \mathrm{~min}$; annealing at $36^{\circ} \mathrm{C}$ for $1 \mathrm{~min}$; elongation or extension at $72^{\circ} \mathrm{C}$ for $2 \mathrm{~min}$; final extension at $72^{\circ} \mathrm{C}$ for $5 \mathrm{~min}$; completion of cycling program (40 cycles), reactions were held at $4^{\circ} \mathrm{C}$. After amplification, aliquots of $12 \mu \mathrm{l}$ of amplification products plus $6 \mathrm{x}$ gel loading dye were loaded in $1.8 \%$ agarose gel for electrophoresis in 1xTAE (40mM Tris, $20 \mathrm{mM}$ Acetic acid, 1mM EDTA) buffer to separate the PCR products containing ethidium bromide. To each PCR amplified product, $1 \mu 1$ of $6 x$ loading dye was added. Molecular weight marker of GeneRuler 100bp DNA ladder was used as standard and electrophoresed alongside with the PCR products. The gel was run at $70 \mathrm{~V}$ until the loading dye reached the gel front. The amplified DNA was viewed under the gel documentation system (BIORAD, Molecular Imager Gel DOCTM XR) and the image was viewed on the monitor. 


\section{RAPD data analysis}

All distinct bands or fragments (RAPD markers) were thereby given identification numbers according their position in gel and scored visually on the basis of their presence (1) or absence (0), separately for each individual and each primer. The scores obtained using all primers in the RAPD analysis were than pooled to create a single data matrix for samples.

The resulting similarity coefficients were used to evaluate the relationships among the cultivars with a cluster analysis using unweighted pair-group method with arithmetic averages (UPGMA) and then plotted in the form of dendrogram. We chose this method of computation over other general similarity indices because of the increased weighting of fragment matches versus that of non-matches (Nei and Li's, 1979). All computations were carried out using the NTSYS-pc, Version 2.1 package (Rohlf 2000, Applied Biostatistics Inc., Exeter Software, NY, USA).

\section{Results and Discussion}

\section{Artificial inoculation}

Experiment was conducted during 2016-17 on twenty cultivars/genotypes by artificial inoculation of $A$. candida sporangial suspension. Record on disease incidence were taken at seven days interval after inoculation $(14,21,28,35$ DAI $)$ and results were presented at table 1 . Results indicated that white rust incidence in the range of 0.37 $7.77 \%, 2.22-17.77 \%, 4.44-26.66 \%$ and $9.62-$ $41.48 \%$ was recorded at $14,21,28$ and 35 DAI respectively. The overall highest average disease incidence $(23.42 \%)$ was observed in CAUMC-12 and lowest disease incidence of $4.16 \%$ was recorded by URBASHI. The present study supported by Li et al., (2008) reported an indirect method of zoospore suspension inoculation and exposure to natural inoculation of Albugo candida spores on Brassica juncea genotypes was adopted in order to identify the useful sources of resistance in Brassica crop.

Hedge and Anahosur (1993) reported that inoculating germinated sporangial suspension on the lower surface of the leaves and covering the plant with polythene for hrs and then exposing them to natural condition during rainy season under the glass house condition is the efficient technique for identifying stable resistant genotypes of mustard against white rust. Bisht et al., (2015) screened 240 Brassica germplasm under field conditions against major disease of rapeseed-mustard. Only 7 were found to show multiple diseases resistant with $5-25 \%$ disease severity against aforesaid diseases.

\section{RAPD analysis of cultivars or genotypes}

RAPD analysis on twenty cultivars or genotypes of rapeseed and mustard using 3 RAPD primers showed that OPB-01 has the highest polymorphic information content.

The banding patterns of twenty rapeseed and mustard cultivars/genotypes using primers OPB-01, OPB-08 and OPD-13 are shown in figure 1, 2 and 3 respectively. Numbers of RAPD markers scored for each individual twenty rapeseed and mustard cultivars/genotypes for each primer are presented in table 2. Simple matching (SM) matrix based on the proportion of shared RAPD bands was used to establish the level of relatedness between the rapeseed and mustard cultivars/genotypes are presented in table 3 . At a distance coefficient of $0.25,20$ cultivars/genotypes were cluster into 2 major clusters, the first major cluster consists of 19 cultivars/genotypes and second major cluster consist of only 1 cultivar/genotype (CAUMC12). 
Fig.1 RAPD profiles of 20 rapeseed and mustard cultivars/genotypes using primer OPB-01

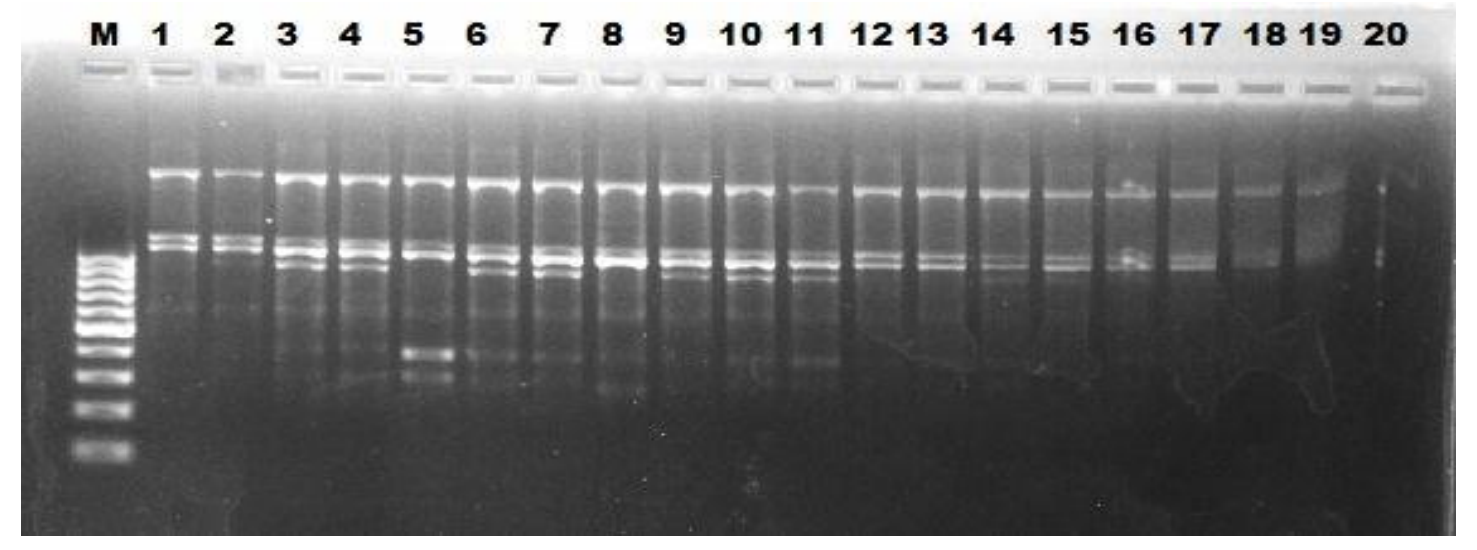

Fig.2 RAPD profiles of 20 rapeseed and mustard cultivars/genotypes using primer OPB-08
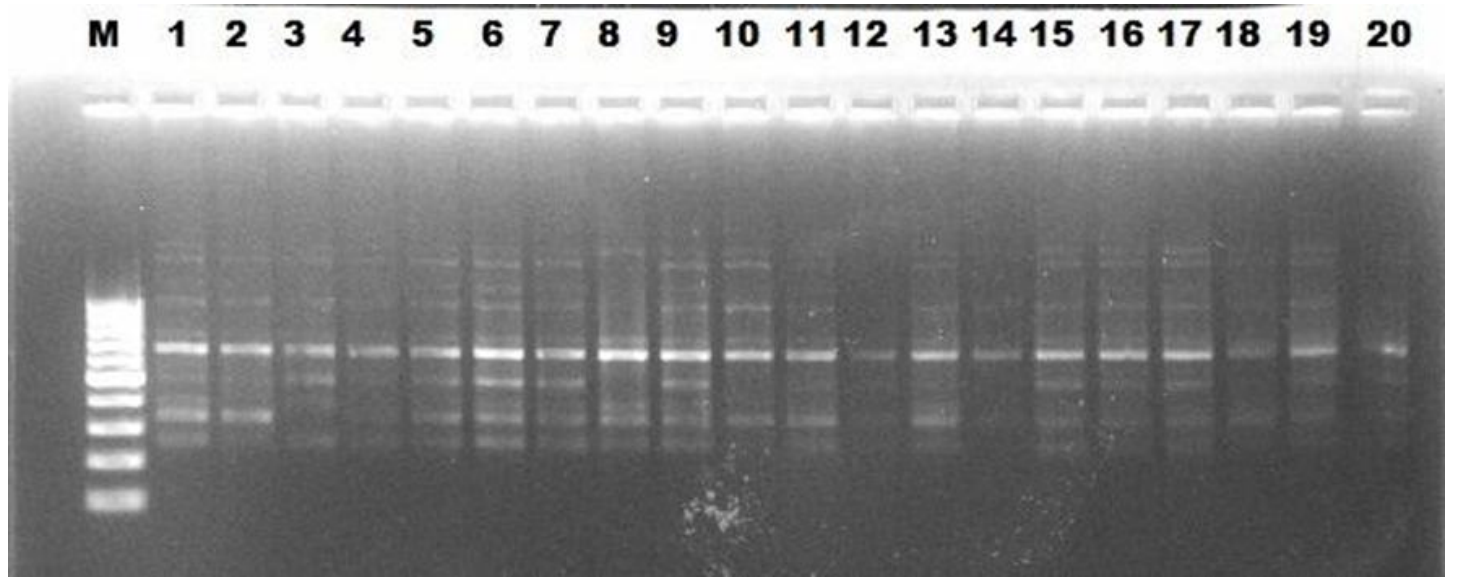

Fig.3 RAPD profiles of 20 rapeseed and mustard cultivars/genotypes using primer OPD-13

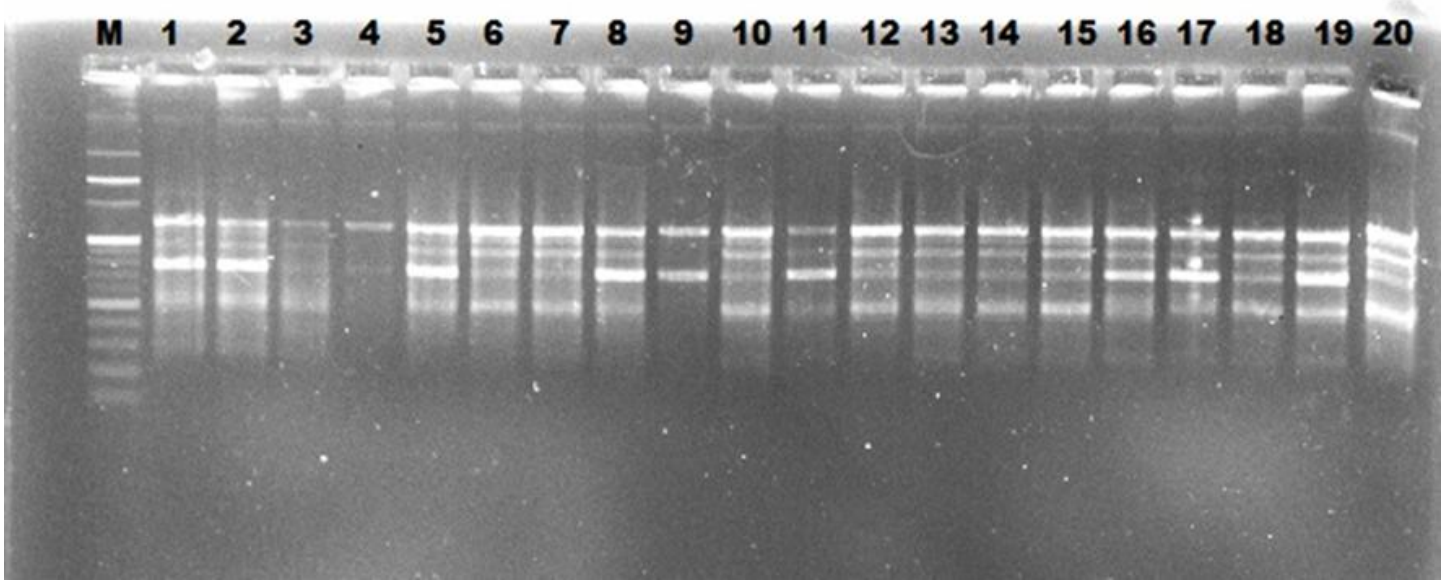

(1, CAULC-1; 2, CAULC-; 3- CAULC-3; 4, CAULC-4; 5, GM-2; 6, KRANTI; 7, URBASHI; 8, PM-21; 9, CAUMC-8; 10, CAUMC-10; 11, CAUMC-11; 12, CAUMC-12; 13, CAUMC-14; 14, CAUMC-15; 15, CAUMC17; 16, CAUMC-20; 17, CAUMC-21; 18, CAUMC-22; 19, CAUMC-23; 20, CAUMC-24). M, Molecular weight marker (100bp DNA Ladder in size) 
Fig.4 UPGMA cluster analysis showing the relationship and diversity among 20 cultivars/genotypes of rapeseed and mustard based on RAPD data

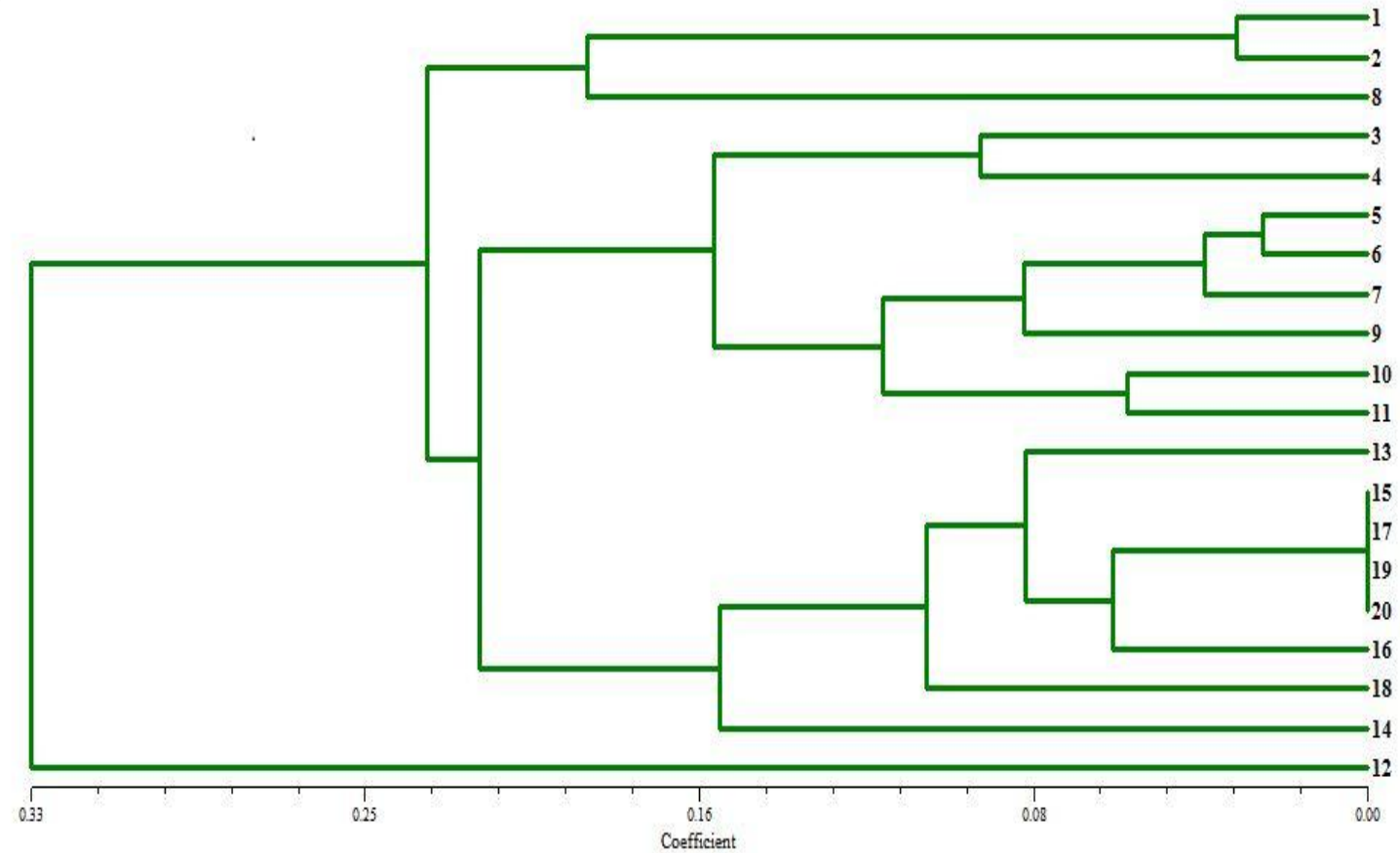

1, CAULC-1; 2, CAULC-2; 3, CAULC-3; 4, CAULC-4; 5, GM-2; 6, KRANTI; 7, URBASHI; 8, PM-21; 9, CAUMC-8; 10, CAUMC-10; 11, CAUMC-11; 12, CAUMC-12; 13, CAUMC-14; 14, CAUMC-15; 15, CAUMC17; 16, CAUMC-20; 17, CAUMC-21; 18, CAUMC-22; 19, CAUMC-23; 20, CAUMC-24.

Fig.5 3D view of principal component analysis based on RAPD data using similarity matrix coefficient of 20 different cultivars/genotypes

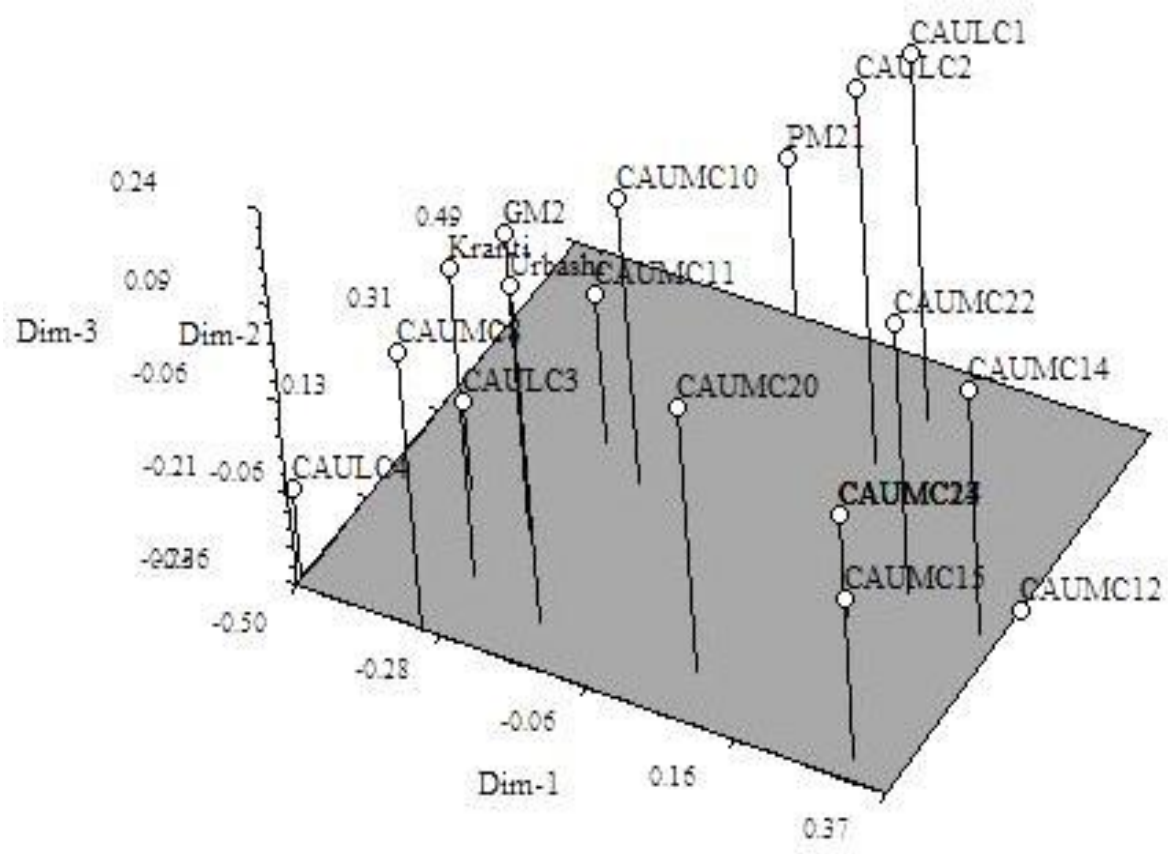


Table.1 Severity of white rust caused by Albugo candida on rapeseed and mustard at cotyledons stage by artificial inoculation

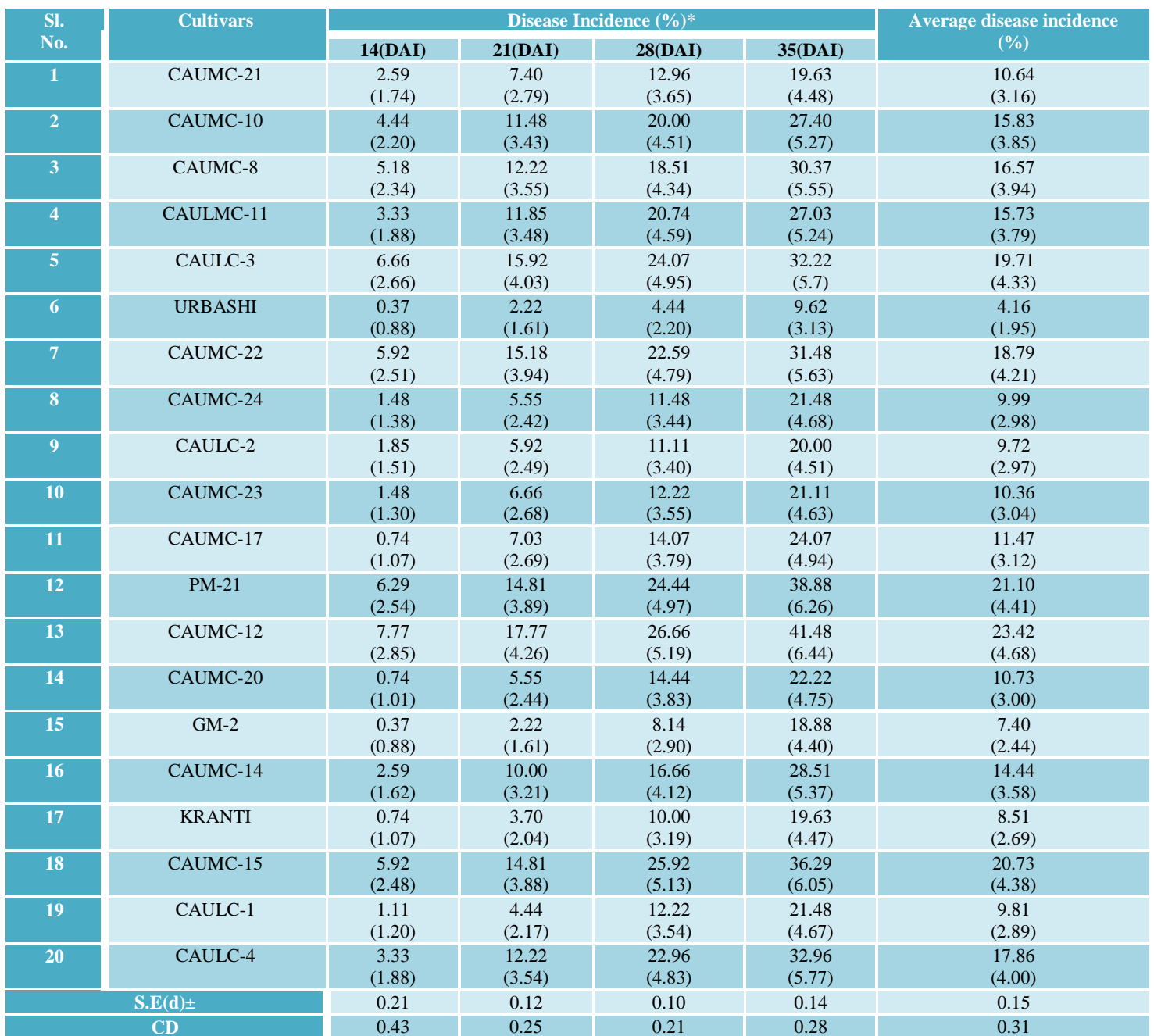

DAI - Days after inoculation

*Mean of three replication

Values in parentheses are $\sqrt{x+0.5}$ transformed values

Table.2 RAPD primers with corresponding band score with polymorphic band, percentage of polymorphism and polymorphic information content observed in 20 rapeseed and mustard cultivars/genotypes
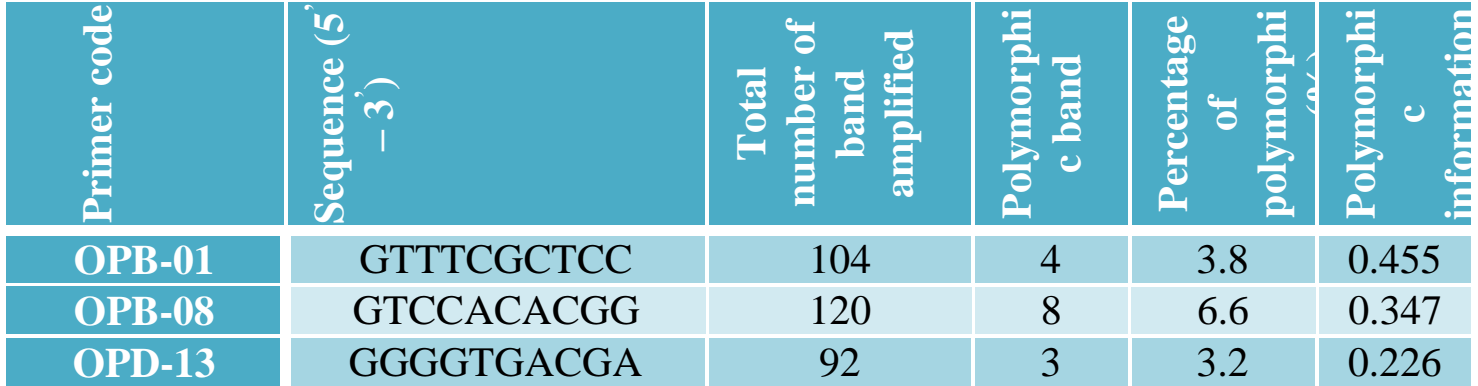

\begin{tabular}{|c|c|}
\hline 104 \\
\hline 120 \\
\hline 92 \\
\hline
\end{tabular}

\begin{tabular}{|l|l|l|}
\hline 4 & 3.8 & 0.455 \\
\hline 8 & 6.6 & 0.347 \\
\hline 3 & 3.2 & 0.226 \\
\hline
\end{tabular}


Table.3 Simple matching (SM) matrix using RAPD data from 20 cultivars/genotypes

\begin{tabular}{|c|c|c|c|c|c|c|c|c|c|c|c|c|c|c|c|c|c|c|c|c|}
\hline & نَّ & 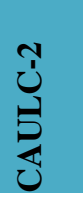 & 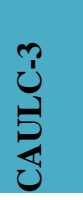 & 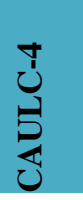 & $\sum_{0}^{N}$ & 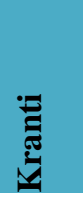 & 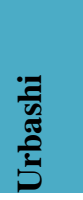 & 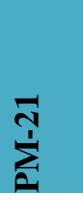 & $\sum_{j}^{\infty}$ & 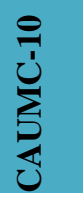 & $\sum^{己}$ & 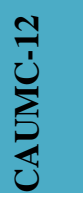 & $\sum_{j}^{J}=$ & 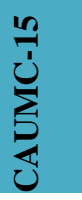 & 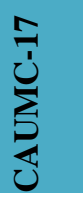 & 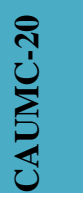 & 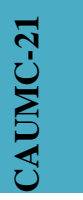 & 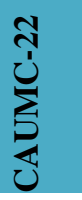 & 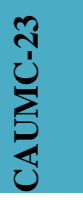 & 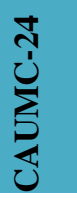 \\
\hline CAULC-1 & 1.00 & & & & & & & & & & & & & & & & & & & \\
\hline CAULC-2 & 0.95 & 1.00 & & & & & & & & & & & & & & & & & & \\
\hline CAULC-3 & 0.64 & 0.68 & 1.00 & & & & & & & & & & & & & & & & & \\
\hline CAULC-4 & 0.50 & 0.55 & 0.86 & 1.00 & & & & & & & & & & & & & & & & \\
\hline GM-2 & 0.73 & 0.68 & 0.73 & 0.77 & 1.00 & & & & & & & & & & & & & & & \\
\hline Kranti & 0.68 & 0.73 & 0.77 & 0.82 & 0.95 & 1.00 & & & & & & & & & & & & & & \\
\hline Urbashi & 0.73 & 0.77 & 0.73 & 0.77 & 0.91 & 0.95 & 1.00 & & & & & & & & & & & & & \\
\hline PM-21 & 0.77 & 0.73 & 0.68 & 0.55 & 0.77 & 0.73 & 0.68 & 1.00 & & & & & & & & & & & & \\
\hline CAUMC-8 & 0.64 & 0.68 & 0.73 & 0.86 & 0.82 & 0.86 & 0.91 & 0.59 & 1.00 & & & & & & & & & & & \\
\hline CAUMC10 & 0.77 & 0.82 & 0.77 & 0.73 & 0.86 & 0.91 & 0.86 & 0.82 & 0.77 & 1.00 & & & & & & & & & & \\
\hline CAUMC11 & 0.68 & 0.73 & 0.77 & 0.73 & 0.77 & 0.82 & 0.77 & 0.82 & 0.77 & 0.91 & 1.00 & & & & & & & & & \\
\hline CAUMC12 & 0.68 & 0.64 & 0.50 & 0.45 & 0.59 & 0.55 & 0.59 & 0.64 & 0.50 & 0.55 & 0.55 & 1.00 & & & & & & & & \\
\hline CAUMC14 & 0.82 & 0.77 & 0.55 & 0.50 & 0.73 & 0.68 & 0.73 & 0.68 & 0.64 & 0.77 & 0.68 & 0.77 & 1.00 & & & & & & & \\
\hline CAUMC15 & 0.64 & 0.68 & 0.64 & 0.59 & 0.64 & 0.68 & 0.73 & 0.68 & 0.64 & 0.77 & 0.77 & 0.77 & 0.82 & 1.00 & & & & & & \\
\hline CAUMC17 & 0.73 & 0.77 & 0.64 & 0.59 & 0.73 & 0.77 & 0.82 & 0.59 & 0.73 & 0.77 & 0.68 & 0.77 & 0.91 & 0.82 & 1.00 & & & & & \\
\hline CAUMC20 & 0.73 & 0.77 & 0.73 & 0.68 & 0.82 & 0.86 & 0.91 & 0.68 & 0.82 & 0.86 & 0.77 & 0.68 & 0.82 & 0.82 & 0.91 & 1.00 & & & & \\
\hline CAUMC21 & 0.73 & 0.77 & 0.64 & 0.59 & 0.73 & 0.77 & 0.82 & 0.59 & 0.73 & 0.77 & 0.68 & 0.77 & 0.91 & 0.82 & 1.00 & 0.91 & 1.00 & & & \\
\hline CAUMC22 & 0.77 & 0.82 & 0.59 & 0.55 & 0.68 & 0.73 & 0.77 & 0.73 & 0.68 & 0.82 & 0.73 & 0.73 & 0.86 & 0.77 & 0.86 & 0.86 & 0.86 & 1.00 & & \\
\hline CAUMC23 & 0.73 & 0.77 & 0.64 & 0.59 & 0.73 & 0.77 & 0.82 & 0.59 & 0.73 & 0.77 & 0.68 & 0.77 & 0.91 & 0.82 & 1.00 & 0.91 & 1.00 & 0.86 & 1.00 & \\
\hline CAUMC24 & 0.73 & 0.77 & 0.64 & 0.59 & 0.73 & 0.77 & 0.82 & 0.59 & 0.73 & 0.77 & 0.68 & 0.77 & 0.91 & 0.82 & 1.00 & 0.91 & 1.00 & 0.86 & 1.00 & 1.00 \\
\hline
\end{tabular}


The first major cluster is divided into 3 minor clusters, the first minor cluster consists of 3 cultivars/genotypes, 2nd minor cluster consist of 8 cultivars/genotypes and the third minor cluster consist of 8 cultivars/genotypes (Fig. 4 and 5). Using 3 RAPD primers, all the twenty cultivars/genotypes were successfully classified except 4 cultivars/genotypes CAUMC-17, CAUMC-21, CAUMC-23 and CAUMC-24 which cluster together, showed moderately less disease resistance i.e. $6.72 \%$, $6.35 \%, 6.24 \%$ and $6.14 \%$ respectively. The present findings agree with Khan et al., (2008) worked on genetic diversity among 45 Indian mustard (Brassica juncea L.) genotypes comprising 37 germplasm collections, five advance breeding lines and three improved cultivars was investigated at the DNA level using the random amplified polymorphic DNA (RAPD) technique. The socio-economic changes in agriculture, easy exchange of seed material between neighboring regions and perhaps close ancestry of these cultivars/genotypes played an additional role towards their lesser diversity. The level of polymorphism detected in present investigation is in agreement to other studies on oilseed brassicas including Nei and Li's (1979), Rabbani et al., (1998) and Cartea et al., (2005) who also observed low level of genetic diversity among oilseed mustard and rapeseed germplasm from India, Pakistan and Spain, respectively using RAPD markers.

The crop suffered yield loss due to several factors among which the fungal disease, white rust caused by Albugo candida is one of the important one. The present investigation was made to understand the variability of rapeseed and mustard in Manipur and Albugo candida reaction to local cultivars/genotypes, RAPD analysis of local cultivars/genotypes. Results from the artificial inoculation of white rust at cotyledons stages on twenty cultivars/genotypes showed variation in disease and incidence and it ranged from 4.16-23.42 per cent. RAPD analysis on twenty rapeseed and mustard cultivars/genotypes using 3 RAPD primers showed variability of rapeseed and mustard cultivars/genotypes of Manipur.CAUMC-12 was totally different from other genotypes/cultivars. The results of the present experiment revealed that the variability which existed among the selected rapeseed and mustard genotypes were much wide.

\section{Acknowledgement}

The authors express sincere thanks to H.O.D. of Plant Pathology, College of Agriculture, Central Agricultural University, Imphal, Dean and college authorities of CAU, Imphal for providing all the necessary materials and technical help during the experimental period.

\section{References}

Bisht K.S., Rana M., Gairola K., Sharma B.C., Tewari A.K. and Awasthi R.P. 2015.Screening Brassica germplasm for resistance to major diseases of rapeseed-mustard. Int. Quarterly J. Life Sci., 10(4): 2111-2119.

Cartea M.E., Soengas P., Picoaga A. and Ordas A. 2005.Relationships among Brassica napus (L.) germplasm from Spain and Great Britain as determined by RAPD markers. Genet. Resour. Crop Evol., 52: 655-662.

DOAC. 2014. Agricultural statistics at a glance. Dir. Econ., and Stat., Dep. Agric. and Corp., Ministry of Agriculture, Government of India.

Farr D.F., Bills G.F., Chamuris G.P. and Rossman A.Y. 1989. Fungi on plants and plant products in the United States. St. Paul, Minnesota: APS Press, pp. 1252.

Hedge V.M. and Anahosur K.H. 1993. Standardization of inoculation 
technique using sporangia to identify mustard genotypes resistant to white rust. Karnataka J. Agric. Sci., 6(4): 408410.

Khan M.A., Rabbani M.A., Munir M., Ajmal S.K. and Malik M.A. 2008. Assessment of genetic variation within Indian mustard (Brassica juncea L.) germplasm using RAPD markers. $J$. Integr. Pl. Biol., 50(4): 385-392.

Li C.X., Sivasithamparam K., Walton G., Fels P. and Barbetti M.J. 2008. Both incidence and severity of white rust disease reflect host resistance in Brassica juncea germplasm from Australia, China and India. Field Crops Res., 106(1): 1-8.

Nei M. and Li W. 1979.Mathematical model for studying genetic variation in terms of restriction endonucleases. Proc. Natl. Acad. Sci., 76: 5269-5273.

Norton D.A. and de Lange P.J. 1999. Coastal areas (nau) recovery plan. Threatened Species Recovery Plan 26. Department of Conservation, Wellington.

Petkowski J.E., Cunnington J.H., Manchinton E.J. and Cahill D.M. 2010. Molecular phylogenetic relationships between Albugo candida collections on the Brassicaceae in Australia. Pl. Pathol., 59: 282-288.
Rabbani M.A., Iwabuchi A., Murakami Y., Suzuki T. and Takayanagi K. 1998.Genetic diversity in mustard (Brassica juncea L.) germplasm from Pakistan as determined by RAPDs. Euphytica, 103: 235-242.

Saharan G.S. 1991.Assessment of losses, epidemiology and management of black spot disease of rapeseed-mustard. In: Proc. GCIRC 8th Inst. Rapeseed Congr., Saskatoon, Canada, 2: 465-470.

Saharan G.S. and Verma P.R. 1992. White rust: A review of economically important species. Ottawa, Ontario, Canada, Int. Dev. Res. Cent., pp. 65.

Trimali A. M. and Kolte S. J. 2012.Induction of host resistance in mustard with nonconventional chemicals against white rust (Albugo candida). J. Pl. Disease Sci., 7(1): 27-31.

Williams H. 1985. White rust, Albugo candida (Pers ex Hook) Kuntze. In: Crucifer Genetics Cooperative (CRGC) Resource Book, University of Wisconsin, Madison, USA, pp. 1-7.

Williams J.G.K., Kubelik A.E., Levak K.J., Rafalski J.A. and Tingey S.C. 1990. DNA polymorphisms amplified by arbitrary primers are useful as genetic markers. Nucleic Acids Res., 28:65316535.

\section{How to cite this article:}

Tusi Chakma, Bireswar Sinha, Th. Renuka Devi and Atom Anupama Devi. 2018. Variability of Rapeseed and Mustard in Manipur and its Reaction to Albugo candida. Int.J.Curr.Microbiol.App.Sci. 7(04): 1377-1385. doi: https://doi.org/10.20546/ijcmas.2018.704.154 